\title{
Workshop on Pliocene Climate
}

by Johan Etourneau and Nabil Khélifi

The warm Pliocene epoch (5-3 million years ago) is often cited as a good analog for the near future climate because of its striking resemblance to the predictions of the "Intergovernmental Panel on Climate Change" for the next decades. Indeed, relative to today, during the Pliocene epoch, surface temperatures were $3-4^{\circ} \mathrm{C}$ warmer, sea level was about 5-40 meters higher, atmospheric $\mathrm{CO}_{2}$ concentrations were relatively similar or slightly higher $(\sim 400 \pm 50 \mathrm{ppmv})$, and ice sheets were restrained to Antarctica. However, since 3.0 Ma ago, the Earth's climate has undergone a major transition from a warm and relatively stable state towards cold conditions marked by amplified glacial/interglacial cycles and widespread ice sheets in the Northern Hemisphere (NHG), and to a lesser extent over Antarctica. The causes and consequences of this global climate transitiondriving warm periods to "icehouse" conditions marked by "Quaternary-style" glacial/interglacial cycles-are still uncertain. Yet, they may include the interaction of several mechanisms tied to oceanic and atmospheric circulations, tectonic-, greenhouse gases-, and biological activity, biogeochemical processes, and changes in Earth's orbit.

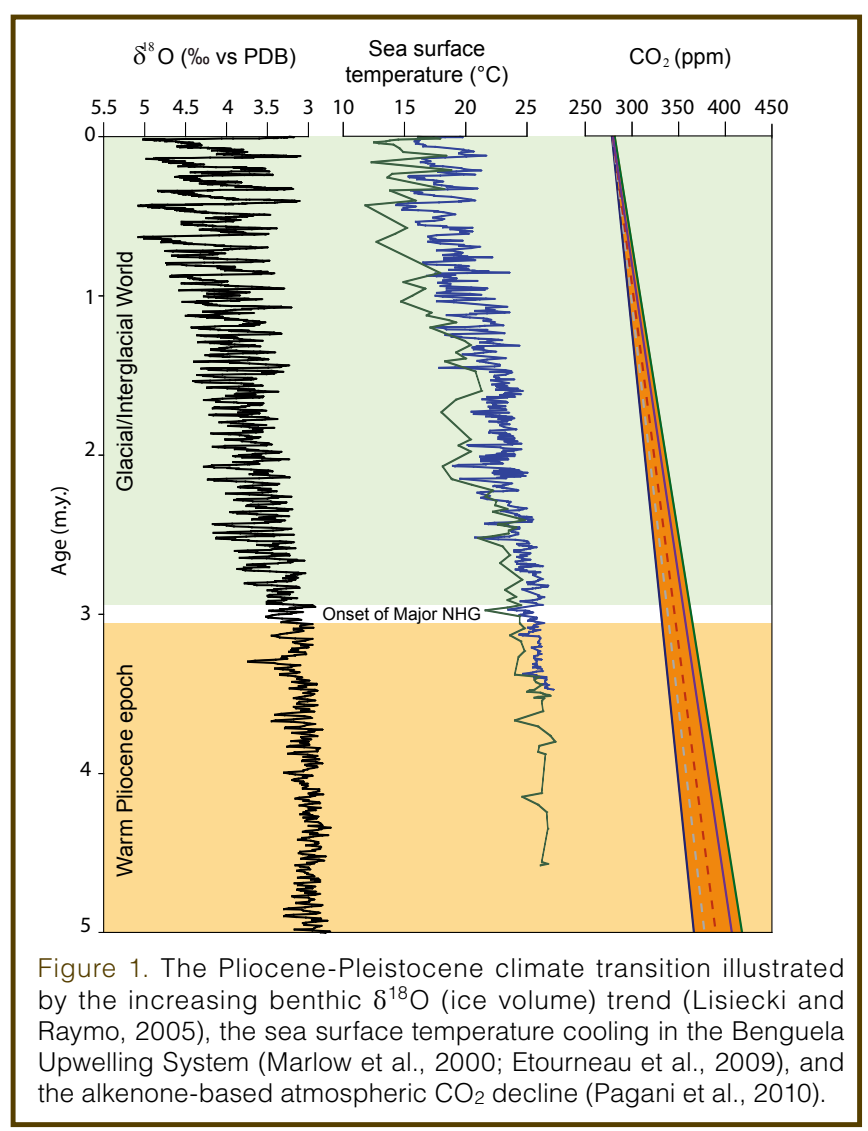

To discuss the different theories explaining this major climate shift, a workshop on Pliocene climate was organized in Bordeaux (France) on 23-25 October 2009. The workshop was sponsored by the European Science Foundation through the "Magellan WorkshopSeries", the "Université Bordeaux 1", the "Observatoire Aquitain des Sciences de l'Univers", the "Institut des Sciences de l'Univers", and together with considerable financial support from Prof. Gerald Haug, ETH Zürich (Switzerland). In total sixty-three participants from eleven countries participated at the workshop, which was divided into two major parts. Three sessions were dedicated to talks and posters, and three sessions were devoted to group discussions. In addition, Prof. Ralf Tiedemann from Alfred Wegener Institute-Bremerhaven (Germany) and Alan Haywood from the University of Leeds (U.K.) presented keynote lectures on reconstructing and modeling Pliocene climate.

During the three days, a series of thirty-three oral presentations and seventeen posters focused on six major key issues: (1) oceanic gateways, (2) changes in Plio-Pleistocene atmospheric $\mathrm{CO}_{2}$, (3) changes in the North Atlantic Circulation and the impact of Mediterranean outflow water on the formation of North Atlantic deep water, (4) North Pacific and southern oceanic/climatic reorganization, (5) tropical/subtropical Pacific conditions, and (6) modeling the Pliocene climate.

Related to these themes, seven discussion groups were in charge of reviewing the main causes for and consequences of the major Pliocene climate change, and to recommend new directions for future research, including drilling targets to be included in the Integrated Ocean Drilling Program (IODP) future objectives.

More specifically, the discussions addressed the following questions.

- What role could the narrowing of the Indonesian Gateway and the closure of the Panama Seaway have played on the thermohaline circulation and Pliocene climate?

- How varied was the atmospheric $\mathrm{CO}_{2}$ through the Plio-Pleistocene climate transition?

- What may have been the major factor(s) controlling atmospheric $\mathrm{CO}_{2}$ changes, and which impact might 


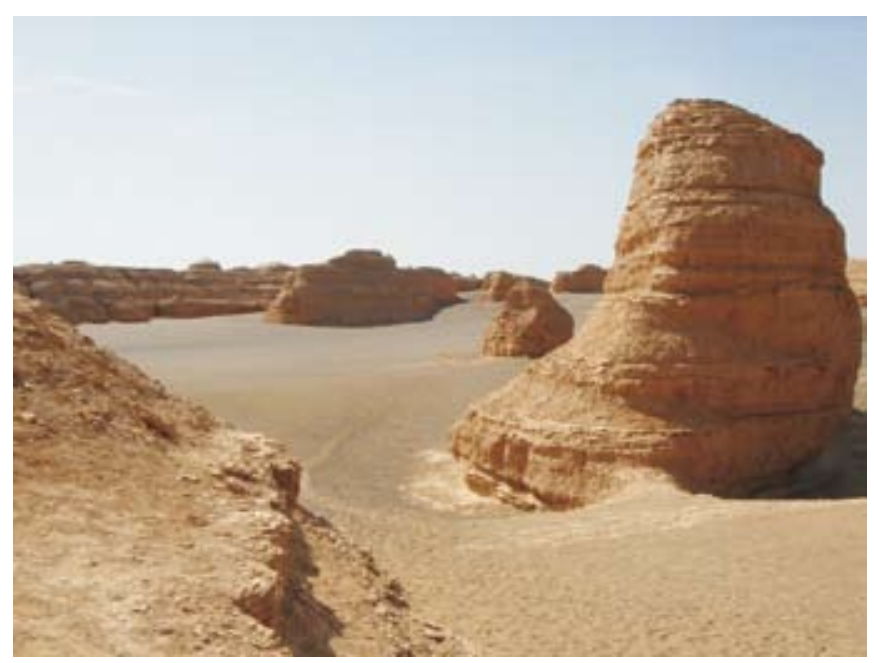

Figure 2. Wind-eroded landforms in the Yadan National Geological Park, Gansu Province, China, resulting from the dryness of a paleolake over the Pliocene-Pleistocene climate transition. Decreasing regional rainfalls are supposed to be closely tied to the Himalayan uplift associated to changes in the atmospheric pattern.

the latter have had on global climate and ice sheet extension?

- Did biogeochemical cycles change in high and low latitudes during the transition from the Pliocene to Pleistocene time, and to what extent might they have impacted on greenhouse gas levels?

- How did the reorganization of the atmospheric circulation affect monsoon system variability and tropical/subtropical/polar precipitation rates over the last 4.0 Ma?

- How can we improve on the currently used models for reconstructing Pliocene climate?

The discussions gave rise to a unanimous consensus: the data spanning the Pliocene are missing in several key sectors of the world ocean, and such data are absolutely needed to further investigate what caused the climate to dramatically cool and generate widespread glaciations in the Northern Hemisphere over the Plio-Pleistocene transition.

A group was specifically tasked with collecting propositions from all participants to define near-future drilling targets. It is clear that the lack of several proxy records from key locations (e. g., bottom and sea surface temperatures, water mass origin, productivity, ocean mixing, $\mathrm{CO}_{2}$ levels, and most importantly a reliable sea-level record covering the last $5.0 \mathrm{Ma}$ ) prevents the scientific community involved in Pliocene studies to further explore the causes and consequences of this climate shift. For instance, only one IODP site 806 in the western equatorial Pacific is available to constrain Plio-Pleistocene changes in the entire warm pool conditions. Also, well dated, located, and preserved ocean records for reconstructing African and South Asian climates are too scarce. Oceanic sedimentary archives from East Africa are particularly crucial for a better understanding of the links between hominid evolution and the African climate during the Pliocene.
Another challenge is the poor knowledge of the extent of ice sheets in the northern high latitudes during the Pliocene. Future IODP drilling campaigns need to be planned in the Arctic Ocean. Given the importance of oceanic gateways in controlling the global thermohaline circulation system, it was also concluded that drilling north of the Bering Strait and offshore Indonesia and Panama is also needed. In addition, to better understand the role of the northern and southern polar oceans in the Pliocene cooling, future IODP drilling should be expanded into the Pacific and Indian parts of the Southern Ocean as well, particularly around and within the polar front system.

After three days of discussions, several participants suggested that workshops on Pliocene climate become a regular event (every three years?) addressing, among other issues, the interactions between data and modeling. The workshop also strongly encouraged participants to submit proposals for future IODP expeditions targeting critical locations to understand Pliocene climate changes.

Further information about the program, talks and posters can be obtained from the workshop homepage: http://www. plioclimworkshop.com.

\section{References}

Etourneau, J., Martinez, P., Blanz, T., and Schneider, R., 2009. Pliocene-Pleistocene variability of upwelling activity, productivity, and nutrient cycling in the Benguela region. Geology, 37:871-874.

Lisiecki, L.E., and Raymo, M.E., 2005. A Pliocene-Pleistocene stack of 57 globally distributed benthic $\delta^{18} \mathrm{O}$ records. Paleoceanogr., 20:PA1003, doi:10.1029/2004PA001071.

Marlow, J.R., Lange, C.B., Wefer, G., and Rosell-Melé, A., 2000. Upwelling intensification as part of the Pliocene-Pleistocene climate transition. Science, 290:2288-2291.

Pagani, M., Liu, Z., LaRiviere, J., and Ravelo, A.C., 2010. High Earth-system climate sensitivity determined from Pliocene carbon dioxide concentrations. Nature Geosci., 3:27-30, doi:10.1038/NGEO724.

\section{Authors}

Johan Etourneau, Christian-Albrechts-Universität zu Kiel/ Université Bordeaux 1, $24118 \mathrm{Kiel} / 33405$ Talence, Germany/ France, e-mail: je@gpi.uni-kiel.de.

Nabil Khélifi, Christian-Albrechts-Universität zu Kiel, 24118 Kiel, Germany, e-mail: nk@gpi.uni-kiel.de.

\section{Photo Credit}

Fig. 2: J. Etourneau 